\title{
SEASONAL AND PERIODIC AUTOREGRESSIVE TIME SERIES MODELS USED FOR FORECASTING ANALYSIS OF RAINFALL DATA
}

\author{
Sukhpal Kaur \\ Research Scholar, Guru Kashi University, Talwandi Sabo, \\ Bathinda, Punjab, India \\ Dr. Madhuchanda Rakshit \\ Assistant Professor, Applied Science Department, Guru Kashi University, \\ Talwandi Sabo, Bathinda, Punjab, India \\ *Corresponding Author: sukhpakaur.sond@gmail.com
}

\begin{abstract}
The amount of rainfall received over an area is an important factor in assessing availability of water to meet various demands for agriculture, industry, irrigation, generation of hydroelectricity and other human activities. In our study, we consider seasonal and periodic time series models for statistical analysis of rainfall data of Punjab, India. In this research paper we apply the Seasonal Autoregressive Integrated Moving Average and Periodic autoregressive model to analyse the rainfall data of Punjab. For evaluation of the model identification and periodic stationarity the statistical tool used are PeACF and PePACF. For model comparison we use Root mean square percentage error and forecast encompassing test. The results of this research will provide local authorities to develop strategic plans and appropriate use of available water resources.
\end{abstract}

Keywords: Encompassing Test, PAR, PeACF, PePACF, RMSPE, SARIMA

Cite this Article: Sukhpal Kaur and Dr. Madhuchanda Rakshit, Seasonal and Periodic Autoregressive Time Series Models Used for Forecasting Analysis of Rainfall Data, International Journal of Advanced Research in Engineering and Technology, 10 (1), 2019, pp 230-242.

http://iaeme.com/Home/issue/IJARET?Volume=10\&Issue=1

\section{INTRODUCTION}

Autoregressive Integrated Moving Average (ARIMA) model is proposed by Box and Jenkins [6] and they gives detail knowledge about ARIMA and Seasonal ARIMA models in their book. Franses H. P. \& Paap [13] discussed in their book about periodic time series models. In recent time there has been considerable research in the development of time series models with seasonal or periodic properties in metrological and hydrological area. These periodic models have been introduced earlier in the article of Hannan [15] and mostly spread in geophysics and 
environmental studies. In the past decades there are various researchers provide literature on univariate periodic time series models includes Gladyshev [14], Jones and Brelsford [19], Pagano [26], Troutman [35], Tiao and Grupe [34] and many more . On evaluating forecasts from PAR models there are several studies like Novales and Flores de Frute [25], Wells [41], Herwartz [16], [17] and Frances and Paap [12] and they yield mixed results.

In periodic modeling we find the various applications such as fourier parameterisation of periodic ARMA model is applied by Lund, Shao and Basawa [24] for daily time series of temperature data. Dudek A. E. [8] et.al find the PARMA methods based on Fourier representation of periodic coefficients. Tesfaye, Meerschaert and Anderson [33] has applied this periodic ARMA modelling on monthly river flows. Recently Ursu E. et.al have used PAR model identification using genetic algorithms and also have done work on application of periodic autoregression process to the modelling of the Garonne river flows[36], [37]. We also find the various application of PAR model on river flow [33] and stream flow [29], [40]. Sarnaglia A. J. Q. et. al have used robust estimation process for the periodic autoregressive in the presence of outliers [28].

Rainfall prediction is an important aspect of climate forecasting. Many researchers have been applied different techniques on accurate rainfall forecasting all over the world. Recently Aftab S et. al [2], B. Kavitha Rani \& A. Govardhan [4] applied data mining techniques, Edwin, A. I and Martins O.Y. [9] applied decomposition technique with ARIMA model and periodic autoregressive model scheme, Sopipan N.[31] applied ARIMA model, Exponential Smoothing and Holt Winter model and many more[8],[20]. Most of the prediction of rainfall data analyzed done by SARIMA (Seasonal Autoregressive Integrated Moving Average) model, like Papalaskaris T. et. al [27], Etuk E. H. and Mohamed T. M [10] in different regions.

There are several studies relating to pattern of rainfall in India. There is no clear trend of increase or decrease in average rainfall in the country studied in [23], [39].There are also lot of research work done on forecasting and analysis of rainfall trends of different regions in India and they have used various statistical techniques and models such as [7],[30],[38]. In 2017 Arvind G. et.al [3] has done research on statistical analysis of Rainfall data and Akash Parmar et al [1] gives a review about machine learning techniques for rainfall prediction. About $80 \%$ of the rainfall in India occurs the four monsoon months (June-Sepetember) with large spatial and temporal variations over the country. In India rainfall of July month is very much crucially for the agricultural crop production. The production of seasonal crops particular under rain fed condition is closely linked with amount and distribution of rainfall. Punjab is agricultural state of northern India. It has played a prominent role by self sufficiency in food grains by wheat and paddy. Some research has been carried out on analysis of rainfall in region of Punjab. Singh R. \& Pal R.K [32], Kumar R. \& Bhardwaj A.[22] and Krishan G. et, al [21] have studied about the analysis of rainfall in Punjab.

In this paper we used seasonal and periodic autoregressive models for forecasting rainfall of Punjab. The study is execute with the following objectives: (i) to develop autoregressive time series models for rainfall of Punjab; (ii) to validate and find future values using developed time series model and finally to assess the change of quarterly rainfall in developed time series. This study aims to provide forecasting information of rainfall data in various districts of Punjab. Autoregressive models is applied to analyze the rainfall of Punjab and for analysing we used R software. For calculating the accuracy of our result on the basis of Root mean square percentage error and forecast encompassing test. 


\section{SOURCES OF DATA}

The source of rainfall data in our study is India Metrological Department (IMD), Chandigarh. IMD provide metrological data for various research and development activities in the fields of like Monsoon, Climate Change and Agricultural Meteorology. The geography and subtropical latitudinal location of Punjab lead to large variations in temperature. There are three main seasons of Punjab i.e. Summer Season, Rainy Season and Winter Season. Punjab's rainy season is start from July as monsoon currents generated in the Bay of Bengal. Our study focus on rainy season of Punjab. We collect our data form IMD, Chandigarh period from 2000 to 2017.

\section{METHODOLOGY}

Time series model can be divided into two components deterministic and stochastic. The deterministic component use for forecast of time and chance independent future events, while the stochastic component use for determination of the chance and chance dependent effects. Deterministic component are either periodic or non periodic in nature. The periodic nature of a deterministic component is identify by its cyclic pattern, which exhibits an oscillatory movement and it is repeated over a fixed interval of time and the non periodic component is identify by its trend. Although stochastic component consists of irregular oscillation and random effects.

There are different approaches to modelling and forecasting seasonal time series. One approach gives Box and Jenkins [6] and on moving average models for double differenced time series which is known as a Seasonal ARIMA (SARIMA) models. Another approach assumes that seasonal time series can be decomposed into trend, cycle, seasonal and irregular components, it reduced forms of the resultant models and have many similarities with the aforementioned SARIMA models. Another approach is based on seasonal variation and it is described by allowing the parameters in an autoregression to vary with the seasons i.e. called Periodic Autoregression (PAR) model.

\subsection{Mathematical formation of SARIMA Model}

The difference of the series $\left\{X_{t}\right\}$ at lag $\mathrm{s}$ is a convenient way of eliminating a seasonal component of period 's'. When we fit an $\operatorname{ARMA}(\mathrm{p}, \mathrm{q})$ model $\phi(B) Y_{t}=\theta(B) Z_{t}$ to the differenced series $Y_{t}=\left(1-B_{s}\right) X_{t}$, then the model for the original series is

$$
\phi(B)\left(1-B_{s}\right) X_{t}=\theta(B) Z_{t}
$$

This is a special case of the general seasonal ARIMA (SARIMA) model defined as follows:

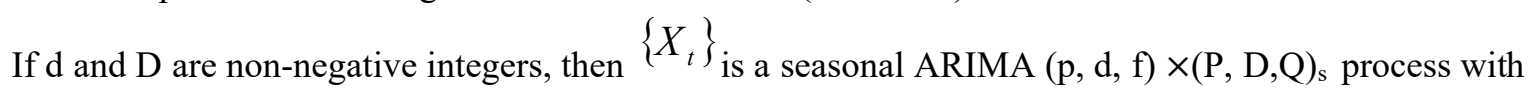
period $\mathrm{s}$ if the differenced series $Y_{t}=(1-B)^{d}\left(1-B_{s}\right)^{D} X_{t}$ is ARMA process defined by

$$
\begin{aligned}
& \quad \phi(B) \Phi\left(B_{s}\right) Y_{t}=\theta(B) \Theta\left(B^{s}\right) Z_{t},\left(Z_{t}\right)_{\sim W N}\left(0, \sigma^{2}\right) \\
& \quad \text { Where } \phi(z)=1-\phi_{1 Z}-\ldots-\phi_{p Z^{p}}, \Phi(z)=1-\Phi_{1 Z}-\ldots-\Phi_{p Z^{p}}, \quad, \theta(z)=1+\theta_{1 Z}+\ldots+\theta_{p Z^{p}} \text { and } \\
& \Theta(z)=1+\Theta_{1 Z}+\ldots+\Theta_{Q Z^{\varrho}} .
\end{aligned}
$$

\subsection{Mathematical formation of PAR Model}

In a univariate time series $y_{t}$ which is observed quarterly for $\mathrm{N}$ years; i.e., $\mathrm{t}=1,2, \ldots, \mathrm{n}=4 \mathrm{~N}$. A periodic autoregressive model of order $\mathrm{p}$ for $y_{t}$ can be written as 
Seasonal and Periodic Autoregressive Time Series Models Used for Forecasting Analysis of Rainfall Data

$$
y_{t}=\phi_{1 s} y_{t-1}+\ldots+\phi_{p s} y_{t-p}+\varepsilon_{t} \text { or } \widetilde{\phi}_{p s}(L) y_{t}=\varepsilon_{t}
$$

Where $\mathrm{L}$ is the usual lag operator and where $\phi_{1 s}$ through $\phi_{p s}$ are autoregressive parameters, which may take different values across the seasons $\mathrm{s}=1,2,3,4$. The distribution with constant variance $\sigma^{2}$ or for different variances $\sigma_{s}^{2}$ in each season.

The periodic process described by model from above equation is nonstationary, as the variance and autocovariances are time varying within a year. A time invariant form of PAR (p) process is rewrite and as the PAR (p) model considers different AR(p) models for different seasons.

After analysis of our data by using seasonal and periodic autoregressive model we forecast our data. We check accuracy of forecasting use error measure gives us a summary of the skill and capability of the forecast model which made the forecasting. We used error measure which is RMSPE and forecast encompassing test.

$$
R M S P E=\sum_{i=1}^{n} \sqrt{\frac{\left(\hat{y}_{i}-y_{i}\right)^{2}}{n} \times 100}
$$

Where $\hat{y}$ is a vector of $\mathrm{n}$ forecast values, $\mathrm{y}$ is the vector of the true values, $\mathrm{n}$ is the size of the out of sample.

The forecast encompassing test for forecast accuracy is developed by Diebold and Mariano(1995) and they have calculated applied work in forecast comparison. The DM-test is based on loss differential between the models i.e. $d_{t}=e_{0, t}^{2}-e_{k, t}^{2}$. To test the null hypothesis we assumed that both the forecast models are equal in nature is given as equal forecast accuracy $H_{0}: E\left(d_{t}\right)=0$. The DM statisitic is:

$$
D M=P^{1 / 2} \frac{\bar{d}}{\hat{\sigma} D M}
$$

Where $\bar{d}$ is the average loss differential, $\mathrm{P}$ is the out of sample size, the $\hat{\sigma} D M$ is the squared root of long run variance of $d_{t}$. The test statistics DM is asymptotically $\mathrm{N}(0,1)$ distributed.

\section{GRAPHIC ANALYSIS OF DATA}

In this section we analyzed the graphic reperesentation of rainfall data. Firstly we plot the boxplot of data monthly as well as quarterly for identifying the outliers in data. Figure 1 below the box-plot for monthly and quarterly rainfall data for checking the presence of outliers in time series. 

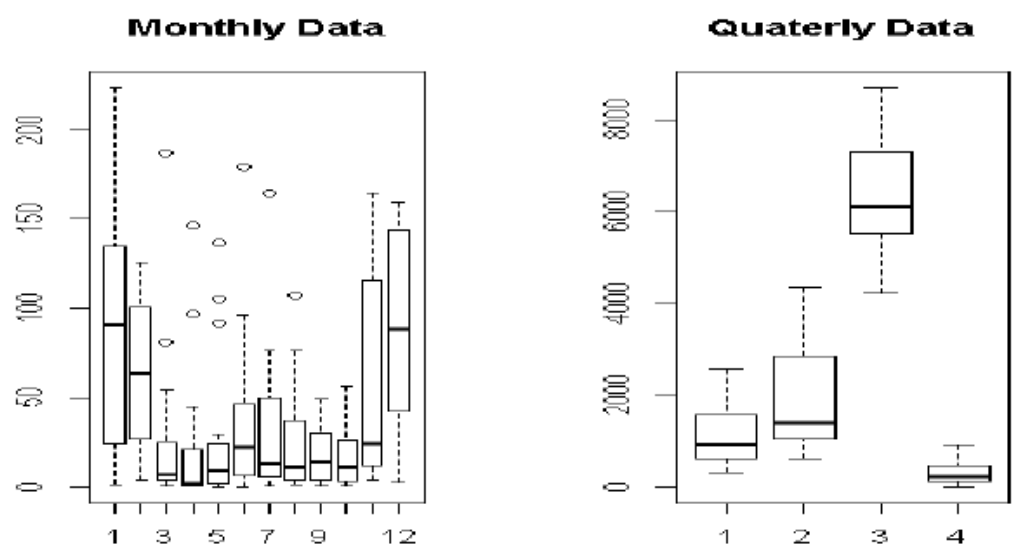

Figure 1: Graph of box-plot

Above graph of monthly data show few observation that can be identified as outliers. But when we take quarterly data there is no shows any observation outside the box-plot therefore we are taking quarterly data for analyzing. In above section 2 we discuss information about the source of data. Following figure 2 shows the graphical representation of data:

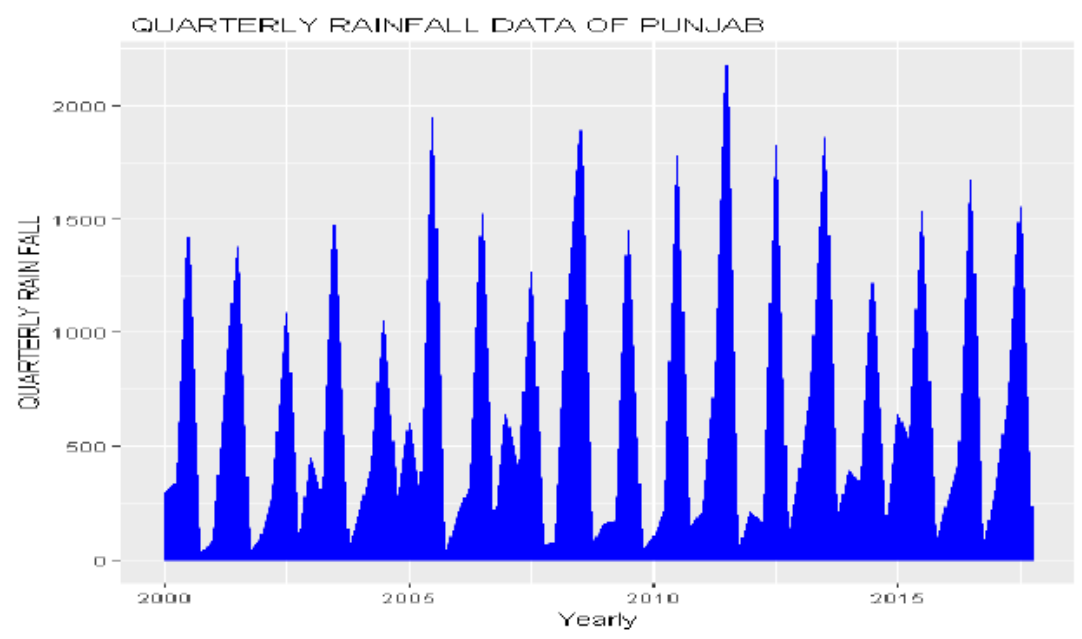

Figure 2: Graph of Quarterly Rainfall Data

\section{AUTOCORRELATION FUNCTION FOR SEASONAL AND PERIODIC AUTOREGRESSIVE MODELS}

The Autocorrelation functions plots are widely used in time series analysis and forecasting. These plots are graphically explanation of the strength of a relationship between observation of time series. Here we discuss the autocorrelation functions for both models.

\subsection{Seasonal ARIMA (SARIMA)}

The ACF plot of the quarterly rainfall data is given below: 

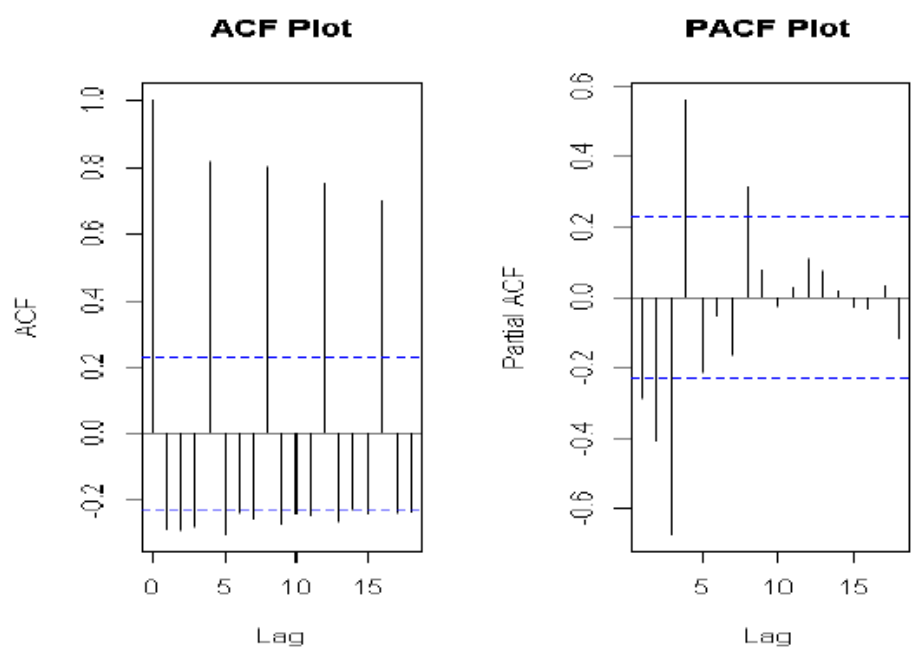

Figure 3: Graph of Autocorrelation Functions

In fig. 3, the ACF plot describe the autocorrelation between observation and also include direct and indirect dependence information between them and show seasonality in data. The ACF and PACF plots shows the order of AR and MA terms. PACF plot shows the direct relationship between observation and its lags.

\subsection{Periodic Autoregressive Model (PAR)}

In PAR model we check the pattern of PeACF and PePACF for PAR model from following plots:
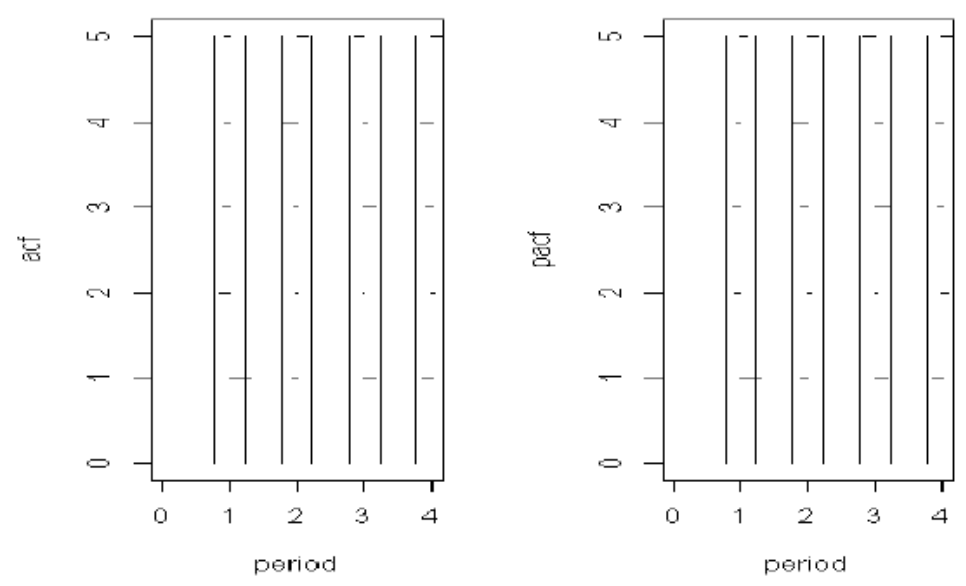

Figure 4: Graph of Periodic autocorrelation function

In fig. 4 we plot the PeACF and PePACF plots of periodic autoregressive models for pure PAR process autocorrelation function becomes zero for lags beyond $\mathrm{p}_{\mathrm{s}}$ and the order of the process can be decided according to the sample of PePACF. Once the presence of periodic correlation has been detected, a suitable PAR model can be selected either by examining plots of PeACF and PePACF or by using information criterion methods i.e. AIC or BIC. 


\section{STATIONARITY TEST}

In most widely used stationary test in time series analysis is Augmented Dicky Fuller Unit Root test. In ADF test has alternative hypothesis can be taken as the series is stationary. When we apply the test on our data we obtain p-value is 0.01 .

\section{MODEL BUILDING PROCEDURE OF SARIMA}

Analysis of time series dealt with stationary time series data and fitting of seasonal autoregressive integrated moving average model for performing the steps of modeling. In this section we discuss the following steps for model building.

Decomposition of time series - Time series decomposition used for check the observation, seasonal effect or variation occurred in series and following figure shows the decomposition of our time series data.

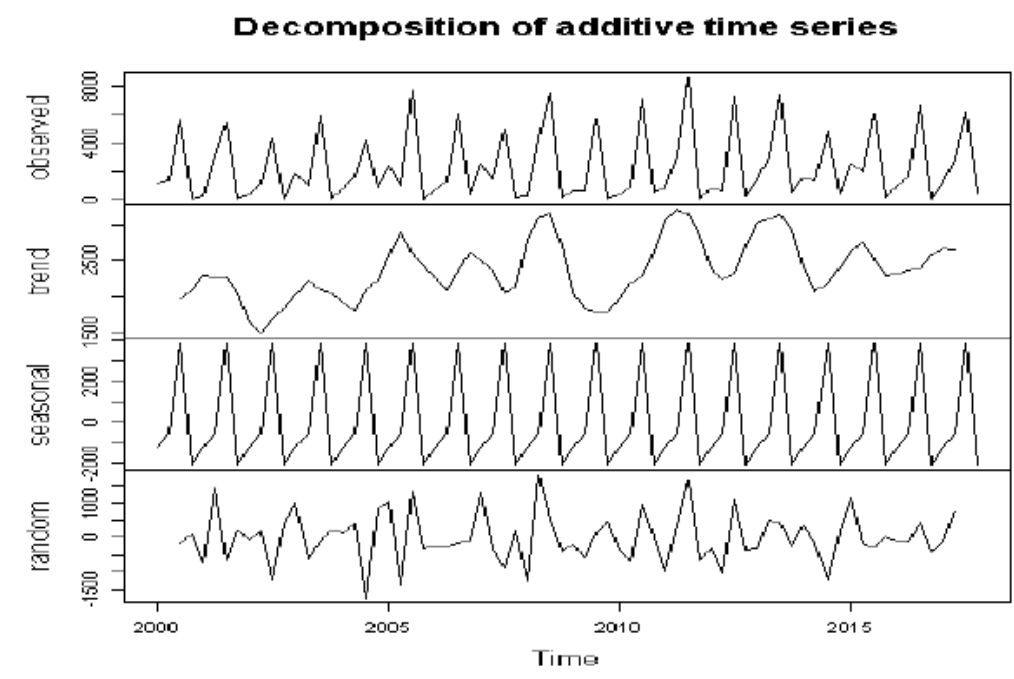

Figure 5: Decomposed time series plot of rainfall data

From above fig. 5 we observed existence of seasonal variation in the series which is constant over time, similarly for the observation of decomposed time series, the random effect change with respect to time.

- Model Identification - The model development process begins by examine the original plot of ACF, PACF and test of the raw data to be sure that it is stationary.

- Model Estimation - The model estimation procedure for choossing the model with the minimum AIC, AICc and BIC and find the best model for our purpose.

Table 1. Parameter estimation of the best fit model SARIMA $(3,0,0)(1,0,1)[4]$

\begin{tabular}{cccccc}
\hline & Ar1 & Ar2 & Ar3 & Sar1 & Sar2 \\
\hline Coefficients & - & - & - & - & - \\
& 1.2885 & 0.7966 & 0.3384 & 0.5150 & 0.8558 \\
S. E. & 0.1131 & 0.1662 & 0.1450 & 0.2291 & 0.1366 \\
\hline
\end{tabular}

In above table 1 we summarised the best SARIMA $(3,0,0)(1,0,1)[4]$ model with mean zero on the basis of minimum information ciretion.

Diagnositic Checking - In time series analysis after selecting the best model fit, we daigonised the residuals analysis. We assume that the best model residuals must follows a white noise process means that the residuals have zero mean, constant variance and also uncorrelated. 

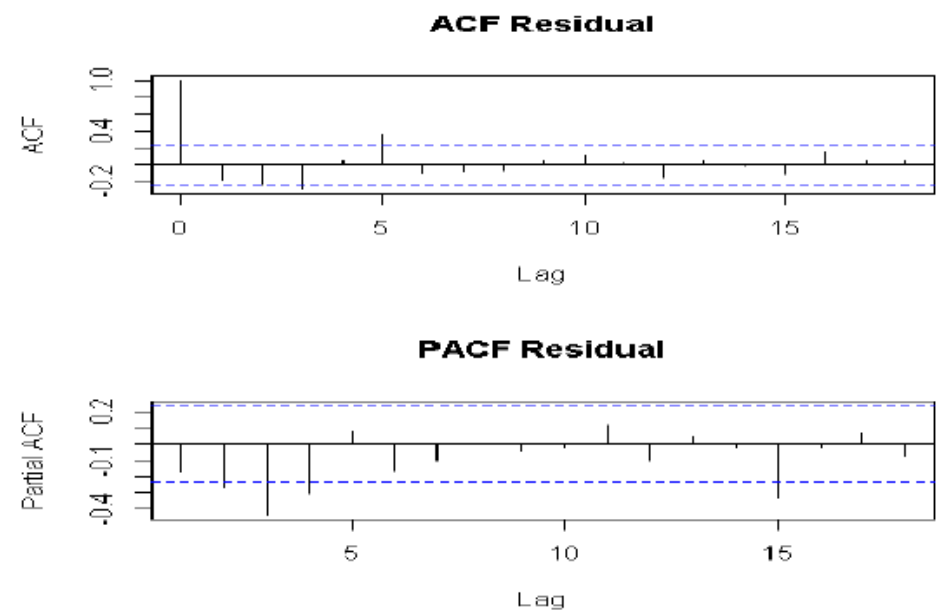

Figure 6: Graph of Residuals Checking

From above fig. 6, the ACF and PACF of the residuals of the model shows that autocorrelation of the residuals are almost zero and uncorrelated, we find very few spikes out side the boundary. We can say that our resulting model is good for forecasting.

\section{MODEL BUILDING PROCEDURE OF PAR}

The PAR models extended class of autoregressive(AR) models by allowing the autoregressive parameters to vary with the seasons. If the number of seasons should be one then PAR model become AR model. In this section we gives the steps for analysing data using PAR model.

Model Identification - We trace seasonal component and seasonal variability of our data in sec. 4 of graphic analysis of data. To stabalized the series we transform the series by taking difference. The presence of periodic correlation in time series has detected by examing the plot of PePACF, In section V, autocorrelation function for seasonal and periodic autoregressive model is explained or it can be done by using information criterion.

Model Estimation and Order Selection - For this estimation and order selection we select the lowest value of AIC and BIC criteria. On the basis of this method order of model is one. Results of order selection is based on table 2 as given below:

Table 2: Periodic Autoregressive order selection

\begin{tabular}{ccccc}
\hline Criterion & \multicolumn{5}{c}{ Periodic Autoregressive Order } \\
& $\mathbf{1}$ & $\mathbf{2}$ & $\mathbf{3}$ & $\mathbf{4}$ \\
\hline AIC & 1134.293 & 1149.518 & 1163.444 & 1171.681 \\
BIC & 1180.903 & 1187.498 & 1192.675 & 1192.046 \\
$F\left(\phi_{p+1, s}=0\right)$ & 0.19 & 1.26 & 1.41 & 1.32 \\
P-value & 0.94 & 0.29 & 0.24 & 0.27 \\
\hline
\end{tabular}

We are also test the periodicity in the autoregressive parameters of the model, we applied F-test for the null hypothesis of non- periodicity, $\phi_{i s}=\phi_{i}$ for $s=1,2, \ldots, 4$ and $i=1,2, \ldots, p$. The results of the test rejected the null hypothesis at $5 \%$ level of significance that means periodic model fits better to the data rather than an AR model, which is constrained to seasonally constant parameters. 
Test for a Unit Root - The multivariate representation of data obtained on the basis of eigen values which provide the information on the prospective unit roots. From the results it is clear that only one positive value is less than one hence it seems that there is no unit root. To check whether a unit root exist or not we apply the Likelihood Ratio test for a single unit root in PAR model.We apply the test and check positive and negative seasonal unit root which shows the rejection for existence of unit root.

Model Diagnostic Checking - For residual checking we apply F-statistic test. According to this test we check whether seasonal heterokedasticity exist in the residuals of the fitted model. Our F-test result show that seasonal heterokedasticity is rejected. The ACF of the original time series shows long - memory behaviour and it can also observe that the residual of the first differenced series better than the first and seasonal differenced of the original series.

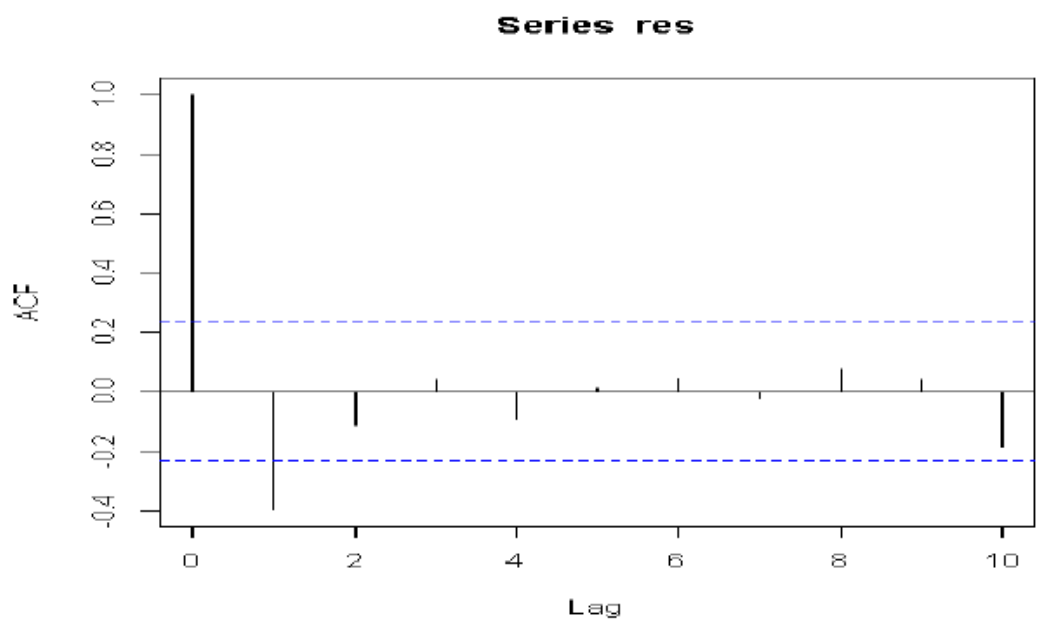

Figure 7: Residual plot of ACF

In above fig 7: acf residual graph shows dotted line for the level of siginificance. It has no residuals present in plot, all spikes are under the boundary line therefore fitted model is best model for forecasting.

\section{MODEL COMPARISION ON THE BASIS OF FORECAST ENCOMPASSING TEST AND ERROR MEASURE}

For comparision between both models, we have taken RMSPE and forecast encompassing test. For analysing our data set based on SARIMA and PAR model the RMSPE and use forecast encompassing test values are obtained.

Table 3: Forecast errors of SARIMA (3) and PAR(1) model

\begin{tabular}{cc}
\hline $\begin{array}{c}\text { Forecast Error } \\
\text { Models }\end{array}$ & RMSPE \\
\hline SARIMA & 13.08 \\
PAR & 10.07 \\
\hline
\end{tabular}

From the table3, it is clear that PAR model is minimum error value as compare to SARIMA. So we conclude that PAR model gives more accurate value as compare to SARIMA. In this paper we apply Diebold-Mariano test for forecast encompassing testing. DieboldMariano test is applied for the null hypothesis for equal forecast accuracy between SARIMA and PAR model. Since the DM statistics converge to a normal distribution, we can reject the null hypothesis at the 5\% level if $|\mathrm{DM}|>1.96$. Otherwise, if $|\mathrm{DM}| \leq 1.96$, we accept the null hypothesis $\mathrm{H}_{0}$. In our result, test value is greater than 1.96 which implies that null hypothesis 
should be rejected and alternative hypothesis accepected means that PAR model has more forecast accuracy than SARIMA model.

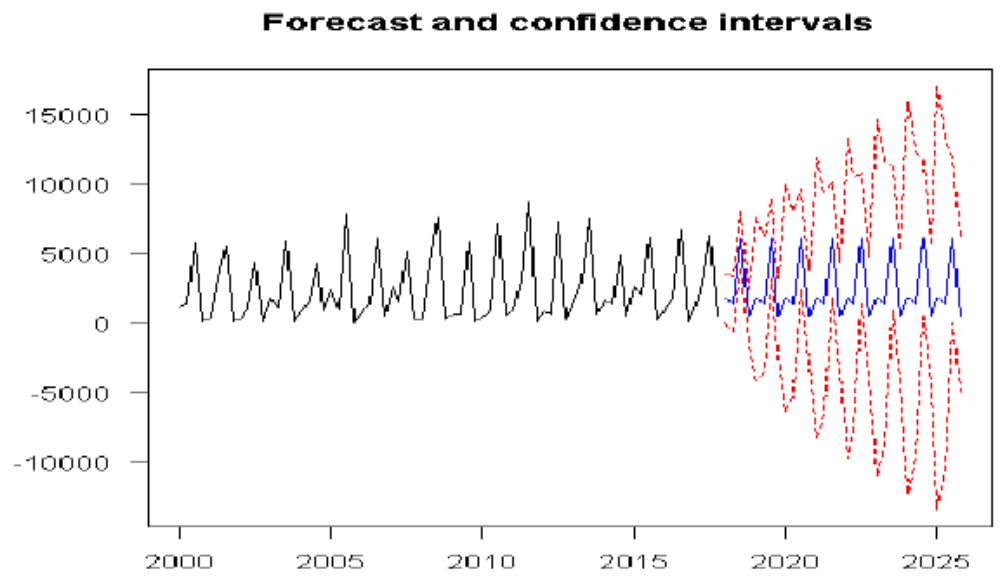

Figure 8: Forecast graph of Rainfall data using PAR model

In fig. 8 we plot the forecast graph of rainfall data and show the 32 quarters ahead forecasts, the upper and lower has $95 \%$ confidence bound, as well as the input and the number of predictions. The minimum predict rainfall value is $472.33 \mathrm{~mm}$ and the maximum predict rainfall value is $6032.39 \mathrm{~mm}$.

\section{CONCLUSIONS}

In this paper we have discussed and forecast the analysis of quarterly rainfall data of Punjab, we have also evaluated their forecasting performance based on error measures and encompassing test. Periodic Autoregressive models are most widely used for modelling seasonal hydrological time series. In our meterological data, we applied seasonal and periodic autoregressive model and compare their performance measures and it is obtained that PAR model is best among the two.

\section{REFERENCES}

[1] Aakash Parmar, Kinjal Mistree \& Mithila Sompura, "Machine Learning Techniques for Rainfall Prediction: A Review", International Conference on Innovations in information Embedded and Communication Systems, 2017

[2] Aftab S., Ahamad M., Hameed N., Bashir M. S. Ali I. \& Nawaz Z., "Rainfall Prediction in Lahore City using Data Mining Techniques", International Journal of Advanced Computer Science and Applications", Vol No. 9 Issue-4, pp. 254-260, 2018

[3] Arvind G., P. Ashok Kumar, S Girish Karthi and C R Suribabu, "Statistical Analysis of 30 Years Rainfall Data: A Case Study", IOP Conference Series: Earth and Environmental Science, Vol No. 80,2017

[4] B. Kavitha Rani \& A. Govardhan, "Rainfall Prediction Using Data Mining Techniques- A Survey" Computer Science and Information Technology, pp. 23-30, 2013

[5] Boswijik, H.P. and Frances, P.H., "Unit roots in periodic autoregressions", Journal of Time Series Analysis, Vol No. 17, pp. 221-245, 1995

[6] Box G. E. P., Jenkins G.M. and Riesel G.C., "Time Series Analysis: Forecasting and Control”, Prentice Hall, 2008 
[7] Dabral P. P., Saring T. Jhajharia D., "Times Series Models of Monthly Rainfall and Temperature to detect climate change for Jorhat (Assam), India”, Global NEST Journal, Vol No. 18, Issue 3, pp. 494-507, 2016

[8] Dudek A. E., Hurd H. and Wojtowicz W., "Periodic autoregressive moving average methods based on Fourier representation of periodic coefficients", WIREs Computational Statisitcs, Vol No. 8, pp. 130-149, 2016

[9] Edwin, A. I. and Martins, O.Y., "Stochastic Characterstics and Modelling of Monthly Rainfall Time Series of IIorin, Nigeria", Open Journal of Modren Hydrology, Vol No. 4, pp. 67-79, 2014

[10] Etuk E., Mohamed T. M., "Time Series Analysis of Monthly Rainfall data for the Gadaref Rainfall Station Sudan”, International Journal of Scientfic research In Knowledge, Vol No. 2, Issue-7, pp. 320-327, 2014

[11] Frances, P. H., "Periodically Integrated Subset Autoregression for Dutch Industrial Production and Money Stock"Journal of Forecasting, Vol No. 12, pp. 601-613, 1993

[12] Frances, P. H. and R. Paap, "Periodic Integration : Further Results on Models Selection and Forecasting”, Statistical Papers, Vol No. 37, pp. 33-52, 1996

[13] Frances, P. H. and R. Paap, "Periodic Time Series Models", Advanced Texts in Econometrics, Oxford University Press, 2005

[14] Gladyshev, E. G., "Periodically correlated random sequence", Soviet Math, Vol No. 2, pp. 38588,1961

[15] Hannan, E. J., "A test for singularities in Sydney rainfall”, Australian Journal of Physics, Vol no.8. pp. 289-297, 1955

[16] Herwartz, H., "Performance of Periodic Error Correction Models in Forecasting Consumption Data", International Journal of Forecasting, Vol No. 13, pp. 421-431, 1997

[17] Herwartz , H., "Performance of Periodic Time Series Models in Forecasting", Empirical Economics, Vol No. 24, pp. 271-301, 1999

[18] Jain, S.K., Vijay Kumar \& Saharia M., "Analysis of rainfall and temperature trends in northest India",International Journal of Climatology, Vol No. 33, pp. 968-978, 2013

[19] Jones, R. H. and Brelsford, W. M., "Time series with a periodic structure”, Biometrika, Vol No. 54, pp. 403-408, 1967

[20] Kar S. C., Acharya N., Mohanty U. C. and Kulkarni M. A., "Skill of Monthly Rainfall Forecasts Over India Using Multi-Model Ensemble Schemes", International Journal of Climatology,Vol No.32, pp. 1271-1286, 2012

[21] Krishan G., Chandniha S. K. and Lohani A. K., "Rainfall trend analysis of Punjab, India using statistical non- parametric test", Current World Enivornment, Vol No. 10, Issue-3, pp. 792-800, 2015

[22] Kumar R., Bhardwaj A., "Probability analysis of return period of daily maximum rainfall in annual data set of Ludhiana, Punjab", Indian Journal Agricultural Research, Vol No. 49, Issue2, pp. 160-164, 2015

[23] Kumar V. Jain S.K. \& Singh Y., "Analysi of long- term rainfall trends in India”, Hydrological Sciences Journal, Vol No.55, Issue-4, pp. 484-496, 2010

[24] Lund, R., Shao, Q. \& Basawa, "Parsimonious periodic time series modeling”, Australian \& New Zealand Journal of Statisitcs Vol No. 48, pp. 33-47, 2006

[25] Novales, A. and R. Flores de Fruto, "Forecasting with Periodic Modles: A Comparison with Time Invariant Coefficient Models", International Journal of Forecasting, Vol No. 13, pp. 393 405, 1997 
Seasonal and Periodic Autoregressive Time Series Models Used for Forecasting Analysis of Rainfall Data

[26] Pagano, M., "On periodic and multiple autoregression", The Annals of Statistics, Vol No. 6, pp. $1310-1317,1978$

[27] Papalaskaris T., Panagiotidis T. Pantrakis A., "Stochastic monthly rainfall time series analysis, modelling and forecasting in Kavala city, Greece, North-Eastern Mediterranean basin",Procedia Engineering, Vol No. 162, pp. 254-263, 2016

[28] Sarnaglia A. J. Q., Reisen V. A. \& Leduc C. L., "Robust estimation of periodic autoregressive processes in the presence of outliers" Journal of Multivariate Analysis, Vol No.101, pp. 21682183,2010

[29] Silveira C. da S., Alexandre A. M. B., Filho F. A. S. and Junior F. C. V.et. al, "Monthly streamflow forecast for national interconnected system(NIS) using periodic autoregessive endogenous models(PAR) and exogenous (PARX) with climate information", Brazillian Journal of Water Resources, Vol No. 22, Issue-30, 2017

[30] Soltani S., Modarres R. \& Eslamian S. S., " The use of time series modeling for the determination of rainfall climates of Iran", International Journal of Climatology, Vol No. 27, pp. 819-829, 2007

[31] Sopipan N., "Forecasting Rainfall in Thailand: A Case Study of Nakhon Ratchasima Province", International Journal of Mathematical and Computational Sciences, Vol No. 8, Issue-11, 2014

[32] Singh R., Pal R. K., "Seasonal quantitative analysis of medium range rainfall forecast for south wertern region of Punjab", Journal of Pharmacognosy and Phytochemistry, Vol No. 7, Issue-5, pp. 2085-2088, 2018

[33] Tesfaye G. Y., Meerschaert M. M. \& Anderson P. L., "Identification of periodic autoregressive moving average models and their application to the modeling of river flows" Water resources research, Vol. No. 42, pp. 1-11, 2006

[34] Tiao, G. and Grupe, M. R., "Hidden periodic autoregressive moving average models in time series data", Biometrika, Vol. No. 67, pp. 365-373, 1980

[35] Troutman, B. M., "Some results in periodic autoregression", Biometrika, Vol No. 66, pp. 219228, 1979

[36] Ursu E. and Turkman, "Periodic autoregressive model identification using genetic algorthims", Journal of Time Series Analysis, Vol No. 33, pp. 398-405, 2012

[37] Ursu E. \& Pereau, “Application of periodic process to the modelling of the Gronne river flows", Stochastic Environment Research and Risk Assessme, Vol No. 30, pp. 1785-1795, 2015

[38] Venkateshwaran M. , Talari G., "Forecasting of Monthly Mean Rainfall in Coastal Andhra", International Journal of Statstics and Applications, Vol No.7, Issue- 4, pp. 197-204, 2017

[39] Vijay Kumar, Sharad K. Jain \& Yatveer Singh, "Analysis of long - term rainfall trends in India", Hydrological Sciences Journal, Vol. No. 55, Issue-4, pp. 484-496, 2013

[40] Wang W., Pieter H. A. J. M., Gelder V. \& Vrijling J. K., "Periodic Autoregressive Model Applied to Daily Stream Flow", International Conference on Hydroinformatics-Liong, Phoon \& Babovic(eds), World Scientfic Publishing, ISBN- 981-238-787-0

[41] Wells, J. M., "Modelling Seasonal Patterns and Long - Run Trends in U.S. Time Series", International Journal of Forecasting, Vol. No. 13, pp. 405-418, 1997

[42] J. El kasri, A. Lahmili, L. Ouadif, L. Bahi, H. Soussi and M.A. Mitach, Comparison of the Relevance and Performance of Filling in Gaps Methods in Rainfall Datasets, International Journal of Civil Engineering and Technology, 9(5), 2018, pp. 992-1000.

[43] Taha Abdelshafy Abdelhakim Khalaf, A Time Series Model for the Exchange Rate Between The Euro (Eur) and the Egyptian Pound (EGP), International Journal of Advanced Research in Engineering and Technology (IJARET), Volume 5, Issue 3, March (2014), pp. 173-182. 


\section{AUTHORS PROFILE}

Dr. Madhuchanda Rakshit, $\mathrm{PhD}$ in Operation research. Presently working as Assistant Professor at Guru Kashi University. She has more than 25 research papers on her own credit. Her area of research is Queuing theory, Time series analysis and Quadratic and fractional programming problems, Transportation problem etc.

Sukhpal Kaur, M.Sc. Mathematics from Punjabi University, Patiala. Presently a research scholar of Applied Science Department, Guru Kashi University. She has published three research papers in international journals and presented few research paper related to her thesis work in various National and International conferences. Her area of research is time series models. 